\title{
A profissão docente sob diferentes concepções psicológicas: 0 enfoque construtivista e o socioconstrutivista
}

\author{
Different psychological conceptions about teaching profession: Constructivist and social \\ constructivist focus
}

Elza Maria Canhetti Mondin ${ }^{[a]}$, Carmen Lúcia Dias ${ }^{[b]}$

\footnotetext{
[a] Doutora em Educação pela Universidade Estadual Paulista (Unesp), membro do Grupo de Pesquisa em Educação da Universidade do Oeste Paulista (Unoeste), Presidente Prudente, SP - Brasil, e-mail: elzamondin@hotmail.com

${ }^{[b]}$ Doutora em Educação pela Universidade Estadual Paulista Júlio de Mesquita Filho (Unesp), docente do Programa de Mestrado em Educação, membro do Grupo de Pesquisa em Educação da Universidade do Oeste Paulista (Unoeste), Presidente Prudente,

SP - Brasil, e-mail:

kkaludias@gmail.com
}

Recebido: 01/09/2011 Received: 09/01/2011

Aprovado: 03/04/2012 Approved: 04/03/2012

\begin{abstract}
Resumo
O presente trabalho constitui um estudo bibliográfico que propõe uma análise compreensiva dos enfoques construtivista e socioconstrutivista na educação brasileira e suas implicações na profissão docente. Com esse propósito, detemo-nos na análise e discussão desses dois grandes núcleos como geradores de questionamentos sobre a complexidade real do contexto educacional. 0 primeiro, o construtivismo, surge como consequência das discussões negativas a respeito do papel reprodutivista da escola; o segundo, o socioconstrutivismo, vem como uma nova perspectiva teórica como uma tentativa de solucionar os problemas educacionais não resolvidos pelo construtivismo Infelizmente, os docentes nem sempre conseguem tirar suficiente proveito dos resultados dessas concepções psicológicas e a realidade de nossas escolas continua dominada pela cultura pedagógica tradicional.
\end{abstract}

Palavras-chave: Profissão docente. Construtivismo. Socioconstrutivismo.

\begin{abstract}
The present paper is a bibliographic study proposing an understanding analysis about the constructivist and social constructivist focus in Brazilian education and its implications in teaching profession. Based on this purpose, the analysis and discussions about these two great nucleuses as acquirement generation about the real complexity of educational context. First, the constructivism arises as consequence of the negative discussions about the reproductivist school role Second, the social constructivism comes as a new theatric perspective in order to find solutions to the education problems that weren't solved by constructivism. Unfortunately, teachers not always get the most out of the result of these psychological conceptions and the reality of our schools goes on controlled by traditional pedagogic culture.
\end{abstract}

Keywords: Teaching profession. Constructivism. Social constructivism.

Psicol. Argum. 2013 jul./set., 31 (74), 483-494 


\section{Introdução}

Uma das grandes questões que se coloca, na atualidade, em relação à educação envolve certa descrença nos referenciais teóricos que justificam a prática de certos métodos de ensino e as concepções a respeito da aprendizagem. É possível identificar na história da educação brasileira um período de questionamento sobre o papel reprodutivista-ideológico da escola enquanto instituição mantenedora de mecanismos de seletividade e desigualdade social. De acordo com Pimentel (1999), a década de 1970 foi considerada uma fase de denúncia que caracteriza o caráter perverso da função da escola enquanto agência reprodutora de uma dominação ideológica. Esse quadro gerou a necessidade de reformulação das práticas pedagógicas para que a escola viesse a cumprir seu papel básico, o de transmitir e produzir conhecimento com fins de democratizar o saber conquistado e acumulado pela humanidade no devir histórico. Uma alternativa amplamente difundida e rapidamente incorporada pelos educadores foi, sem dúvida, a aplicação das ideias construtivistas. Entretanto, é interessante frisar que os procedimentos adotados nem sempre foram acompanhados de críticas de conteúdos fidedignos (não distorcidos). Durante os anos 1980, professores e pesquisadores empregaram intensos esforços na busca de soluções para os problemas de ensino e as ideias de Piaget tornaram-se a tábua de salvação para o campo educacional.

Seria oportuno que os professores:

... começassem a se preocupar com a própria formação. Reaprendendo a apreciar o estudo, temos certeza de que gradativamente terão condições de assumir uma atitude criteriosa e consciente a respeito do pacote de programas de ensino que enfiam goela abaixo sem sequer mastigar. Em outras palavras, façam uma opção teórica, professores (Seber, 1997, p. 19).

A autora explica que é necessário pensar seriamente sobre a parte de responsabilidades que nos cabe. Somos responsáveis pelo crescente automatismo e pela ausência de motivação das nossas crianças. Enfrentar o cotidiano das escolas é difícil para muitas. E, o que é mais trágico, a recusa ao crescimento intelectual é considerada imanente às primeiras etapas da escolarização. Tudo é tão "natural" que poucos se questionam se as crianças terão condições, um dia, de recuperarem a vontade de ler, escrever, questionar os eventos que observam.

\section{0 enfoque construtivista: a posição teórica piagetiana}

De acordo com Souza Filho (2008) apoiando-se em Turner, três enfoques são centrais para a compreensão do posicionamento de Jean Piaget. 0 primeiro diz respeito a como toda entidade biológica possui uma organização interna; do mesmo modo, a cognição humana teria também uma organização própria. 0 segundo trata da organização interna como responsável pelo modo único de funcionamento do organismo, sendo este invariável tanto na criança como no adulto. 0 terceiro informa que a interação entre organismo e ambiente se estabelece por meio dos invariantes modos de funcionamento, há uma adaptação das estruturas cognitivas (processo de adaptação), bem como o desenvolvimento delas (processo de organização).

Evidencia-se na perspectiva evolutiva de Piaget que o comportamento humano adulto e seu aparato cognitivo não podem ser adequadamente compreendidos sem essa perspectiva. Ela compreende uma cuidadosa descrição e análise de estados ontogenéticos sucessivos. 0 que mais se destaca nesse estado são as modificações comportamentais de um funcionamento menos sofisticado para um mais sofisticado, o que justifica a colocação de períodos ou estágios definidos de desenvolvimento (períodos sensório-motor; pré-operatório; operatório concreto e operatório formal). 0 desenvolvimento cognitivo é organizado e dirigido por estruturas mentais compostas por "esquemas de ação" e "operações de caráter lógico-matemático". Esse desenvolvimento refere-se essencialmente às atividades do sujeito, e da ação sensório-motora às operações mais interiorizadas. Lembra Piaget (2008, p. 49):

... o motor é constantemente uma operatividade irredutível e espontânea e esta operatividade não é nem pré-formada de uma vez por todas nem explicável por suas contribuições exteriores da experiência ou da transmissão social: ela é o produto de sucessivas construções, e o fator principal desse construtivismo é um equilíbrio por auto-regulações que permitem remediar as incoerências momentâneas, resolver os problemas e superar as crises ou os desequilíbrios por uma elaboração constante de novas estruturas 
que a escola pode ignorar ou favorecer, segundo métodos empregados.

Com base nessas palavras, Papalia e Olds (2000) esclarecem que o núcleo do comportamento inteligente para Piaget é uma capacidade inata de adaptar-se ao ambiente.

Usando suas capacidades sensoriais e reflexas, as crianças, no início da vida, aprendem e atuam sobre o ambiente que as cerca. Piaget descreve o desenvolvimento mental como uma série de fases ou estágios. Em cada um deles, a criança desenvolve um modo novo de pensar e responder ao ambiente. Dessa maneira, observa-se que cada fase constitui uma mudança de caráter qualitativo de um tipo de pensamento ou comportamento para o outro. E cada uma delas ancora-se na fase anterior e assim constrói os alicerces para a seguinte. 0 desenvolvimento mental, no enfoque piagetiano, ocorre mediante três princípios coordenados entre si: a organização, a adaptação e a equilibração, que operam em todas as fases desenvolvimentais e afetam todas as interações com o ambiente.

0 primeiro princípio, o de organização, refere-se à criação de sistemas de conhecimento cada vez mais complexos. Desde o nascimento, a pessoa organiza o que conhece por meio de representações mentais da realidade, permitindo a ela a compreensão do seu mundo. Nessas representações sucessivas, observa-se a presença de estruturas denominadas "esquemas" que são padrões organizados de comportamento que a pessoa usa para pensar e agir diante de uma situação. 0 segundo, o da adaptação refere-se à maneira como uma pessoa lida com novas informações. Ela envolve duas etapas, a da assimilação, que significa tomar uma informação e incorporá-la em estruturas cognitivas existentes, ou formas de pensar, e outra, a da acomodação, significando que a pessoa muda suas ideias ou estruturas cognitivas em decorrência da inclusão do novo conhecimento.

Os esquemas largamente utilizados no construtivismo piagetiano representam um conceito dos mais difíceis de serem compreendidos. 0 termo "esquema" é frequentemente utilizado como mais ou menos análogo a "conceito", "categoria mental" ou "complexo de ideias".

Por fim, o terceiro princípio, o da equilibração, consiste na busca constante por um estado de equilíbrio explicado pela ausência de conflito entre a pessoa e o mundo exterior e entre as suas próprias estruturas cognitivas. A necessidade do equilíbrio leva a pessoa a mudar de assimilação para a acomodação, ao longo de todo a vida.

Supunha Piaget que no processo da adaptação a criança está sempre lutando por coerência para ficar "em equilíbrio", para chegar a um entendimento do mundo que faça sentido total.

Bee (1996, p. 194) explica que a ideia central de Piaget era:

... de que a criança é uma participante ativa no desenvolvimento do conhecimento, construindo seu próprio entendimento. Esta idéia, talvez mais do que qualquer outra, influenciou o pensamento de todos que seguiram Piaget. A metáfora moderna é a da criança como um "pequeno cientista", engajado numa ativa exploração, buscando entendimento e conhecimento. Ao construir esse entendimento, segundo Piaget, a criança tende a adaptar-se ao mundo que a cerca de maneiras cada vez mais satisfatórias. Na teoria de Piaget, esse processo de adaptação é constituído por vários subprocessos vitais.

Não é difícil perceber que nas ideias piagetianas a respeito do desenvolvimento intelectual aparece sempre a noção de construção do conhecimento. Nos esclarecimentos de Seber (1997), essa concepção de construção não pode ser isolada do desenvolvimento da inteligência. Além do fator hereditário presente no desenvolvimento, a inteligência constitui estruturas próprias, estruturas de conhecimento. Construídas no decorrer das interações, as estruturas cognitivas evoluem mediante a influência mútua de fatores externos, do meio, e de fatores internos, próprios da organização intelectual.

Os objetos a serem conhecidos pertencem à realidade e a inteligência (atividade do sujeito) passa a conhecer gradativamente esses objetos do ambiente por meio de sucessivas construções, permitindo uma aproximação cada vez maior com essa realidade. 0 conhecimento não progride mediante simples recordações de informações dadas, mas principia nas trocas que o sujeito mantém com o mundo. Assim, o conhecer não consiste em copiar o real, mas em agir sobre ele e transformá-lo, de modo a compreendê-lo em função dos sistemas de transformação aos quais estão ligadas essas ações. Qual seria, então, a definição de inteligência no enfoque de Piaget?

0 termo "inteligência", segundo Piaget, indica um coletivo, que designa um grande número de processos e de mecanismos explicados um a um, seguindo a sequência de seus desenvolvimentos.

Psicol. Argum. 2013 jul./set., 31 (74), 483-494 
Em outras palavras, a inteligência representa a coordenação de operações ou de esquemas, o que significa adaptação às situações novas, sendo, portanto, uma construção contínua das estruturas.

Do ponto de vista funcional, Seber explica que

A inteligência constitui uma totalidade organizada que se transforma e ao mesmo tempo se conserva funcionando. Esse funcionamento implica assimilação de informações aos seus esquemas de ação e acomodação desses esquemas às particularidades dos objetos assimilados. Do ponto de vista estrutural, a inteligência vai evoluindo num processo de mobilidade crescente e reversível, como vimos a respeito da coordenação geral dos esquemas (Seber, 1997, p. 79).

A formação de inteligência e a natureza ativa dos conhecimentos enfatizados por Piaget (2008) somente ocorrerá quando o objetivo principal do ensino dirigir-se ao desenvolvimento da própria inteligência, e sobretudo aprender a desenvolvê-la o mais longamente possível, isto é, além do término da vida escolar. As funções essenciais da inteligência consistem na compreensão e invenção, em resumo, construção de estruturas (estrutura do real). Os conhecimentos derivam das ações. Conhecer um objeto corresponde a agir sobre ele e transformá-lo, aprendendo os mecanismos dessa transformação vinculados com as ações transformadoras. Na verdade, é legítimo concluir que o desenvolvimento da inteligência constitui a construção prévia e necessária da eficiência de todo o ensino.

\section{A dificuldade dos docentes nas práticas referenciais piagetianas}

O construtivismo, sem dúvida alguma, abre um novo olhar sobre o aluno e a construção ativa de seu desenvolvimento. Os docentes podem ter, com base nas ideias piagetianas, a possibilidade de reavaliar suas práticas educativas e reelaborar suas concepções acerca da aprendizagem. A teoria de Piaget efetivamente se impõe como um dos estudos científicos mais completos comparados com outros que surgiram no século XX. As suas explicações a respeito da construção do conhecimento repercutiram nas ciências humanas e biológicas, no desenvolvimento da psicologia, nas práticas pedagógicas. Vale comentar, entretanto, o descaso demonstrado por parte de muitos docentes quando se referem à sua obra.
0 ponto que mais tem sido mal compreendido refere-se, conforme Seber (1997), à ideia de construção, de que as estruturas são novas, que nem existiam no sujeito, nem no objeto, mas que são construídas. O conhecimento, conforme a autora, não é predeterminado desde o nascimento da criança, tampouco evolui de fora para dentro mediante, exclusivamente, fatores sociais de troca, mas, ao contrário, é edificado pela criança enquanto interage com o meio.

Montoya (2004) defende que para o educador se afaste do pressuposto de que os conhecimentos podem ser simplesmente transmitidos e aprendidos numa ordem lógica e predeterminada, ele deverá conhecer os processos e mecanismos intelectuais envolvidos na aprendizagem dos conteúdos.

Prossegue o autor,

\begin{abstract}
Embora exista consciência da necessidade desse conhecimento para a ação pedagógica e educacional, o pensamento e a obra desse autor infelizmente foram reduzidos ao desenvolvimento das estruturas lógico-matemáticas, particularmente aos seus estágios sucessivos. Essa forma de leitura contribuiu e muito para o empobrecimento de seu pensamento e limitou, assim, a sua contribuição para a ação educacional (Montoya, 2004, p. 159).
\end{abstract}

É preciso reconhecer que a educação tradicional sempre considerou a criança como um pequeno adulto, em uma visão adultocêntrica; um ser que raciocina e pensa como nós, mas simplesmente desprovido de conhecimentos e de experiências. Sendo a criança apenas um adulto ignorante, o trabalho do professor não era tanto de formar o pensamento, mas de equipá-lo; consequentemente, as matérias ou disciplinas impostas eram consideradas suficientes ao exercício.

Por outro lado, vale considerar que três acontecimentos, segundo Piaget (2008), colaboram para os maus resultados no campo educacional em todos os países: o primeiro revela o aumento vertiginoso do número de alunos, um avanço significativo à demanda escolar, incentivado pelo acesso a todos, de acordo com nossas leis. 0 segundo, uma consequência natural do primeiro, refere-se à dificuldade de recrutamento de pessoal docente suficientemente formado. 0 terceiro refere-se, sobretudo, às novas necessidades econômicas, técnicas e científicas das comunidades em que a instrução pública está sendo organizada. Tais acontecimentos intervêm notavelmente na seleção dos métodos de ensino e 
conduzem a conflitos compreensíveis entre outros métodos verbalistas tradicionais, cuja prática não exige formação avançada; já os métodos ativos se tornam cada vez mais necessários quando se visa a formação de quadros técnicos e científicos dentro do campo profissional docente. Toda teoria do autor em estudo, de acordo com Rappaport (1981), converge para uma visão interacionista. A criança, em um processo ativo de interação, faz uso de mecanismos para compreender o mundo.

Para Piaget (Aebli, 1973), a adaptação à realidade externa depende basicamente do conhecimento. Só o conhecimento possibilita ao ser humano um estado de equilíbrio interno que o torna pronto para adaptar-se ao meio ambiente. Existe para ele uma realidade externa ao sujeito do conhecimento, e é a presença dessa realidade que regula e corrige o desenvolvimento do adaptativo. A função do desenvolvimento não consiste em produzir cópias internalizadas da realidade exterior, mas em produzir estruturas lógicas no sujeito a fim de que atue sobre o mundo de formas cada vez mais flexíveis e complexas.

A aplicação da psicologia de Jean Piaget à didática deve ter seu ponto de partida na tese fundamental segundo a qual o pensamento não é um conjunto de termos estáticos, uma coleção de 'conteúdos de consciência', de imagens, etc., mas um jogo de operações vivas e atuantes. Pensar é operar - quer se trate de assimilar os dados da experiência submetendo-os aos esquemas de atividade intelectual ou de construir novas operações por uma reflexão, 'abstrata' na aparência, isto é, operando interiormente sobre objetos imaginários. A imagem não é o elemento fundamental do pensamento, antes constitui seu suporte, muitas vezes útil, sem dúvida, mas não indispensável (Aebli, 1973, p. 87).

Ainda na visão do autor, quando se diz que o aluno deve conhecer certas matérias, significa que deve aprender a executar certas operações. São sempre as operações que definem as noções, e é sua execução que o ensino deve provocar, primeiro efetivamente e depois sob forma "interiorizada" ou representativa. Vale repetir que Piaget revela a ligação fundamental entre ação e aprendizagem; uma vez que a verdadeira aprendizagem depende da atividade do aluno, "atividade" não representa um acréscimo caprichoso ao currículo para provocar mais prazer às crianças, mas o elemento necessário em toda habilidade de aprendizagem. Alguns princípios piagetianos podem ser úteis e valiosos na prática docente: a) Respeito à produção do aluno - uma ideia consensual, mas que ainda é difícil de ser colocada em prática. Se conhecer é inerente ao ser humano, porque disso depende a sua sobrevivência, todos podem aprender, independentemente da sua idade, sexo, cor, classe social.

b) Espaço para o aluno testar suas hipóteses o conhecer inicia-se com a ação. Conhecemos agindo sobre o objeto a conhecer, seja ele pertencente à realidade concreta ou à realidade abstrata.

c) Trabalho em grupo como facilitador do aprendizado - o conhecer se dá na integração dos indivíduos com os objetos a conhecer e entre os indivíduos. Por isso o trabalho cooperativo é mais fértil.

\section{0 aspecto afetivo das construções cognitivas}

Embora distintas, a vida afetiva e vida cognitiva são inseparáveis, lembra Piaget em sua obra, conforme Seber (1997). 0 ato de inteligência pressupõe uma regulação energética interna como interesse, esforço, facilidade etc. Assim, é possível afirmar que a compreensão de qualquer conteúdo não se concretiza sem a vivência de certos sentimentos e contrariamente não existem afeições sem um mínimo de compreensão. 0 interesse refere-se à relação afetiva entre a necessidade e o objeto de sua satisfação.

A afetividade ou sua privação certamente podem causar a aceleração ou atraso no desenvolvimento cognitivo. Entretanto, isso não significa que a afetividade crie ou modifique as estruturas cognitivas, cuja necessidade permanece intrínseca. Os mecanismos afetivos e cognitivos de fato são indissociáveis, embora distintos.

Essas relações entre os desenvolvimentos cognitivo e afetivo foram percebidas por Piaget (1969), embora ele tenha direcionado suas pesquisas principalmente para o desenvolvimento cognitivo - interesse pelo sujeito epistêmico; "existe, com efeito, um paralelo constante entre a vida afetiva e a intelectual. E este paralelismo se seguirá no curso de todo o desenvolvimento da infância e adolescência" (Piaget, 1969, p. 21).

Emoção e inteligência são duas propriedades inseparáveis da atividade humana. Nenhuma atividade, por mais intelectual que seja, suprime a emoção,

Psicol. Argum. 2013 jul./set., 31 (74), 483-494 
nenhuma situação emocional, por mais intensa que seja, elimina completamente a presença da razão.

Assim, na escola, como em qualquer instância social, o indivíduo está presente como pessoa completa, sujeito de conhecimento, sujeito de afeto. Portanto, a escola não deve negligenciar, subestimar ou até mesmo suprimir o espaço da emoção em suas atividades.

A motivação, o afeto, o prazer, o desprazer, o empenho e o interesse constituem a relação que liga a situação exterior ao nível de construção das estruturas da pessoa. Quando ela se interessa por algo significa que ela está de posse de certas estruturas passíveis de assimilar o que lhe propõem (Seber, 1997). Nenhuma situação exterior é em si mesma interessante, desafiadora, fácil ou difícil, pois tudo depende de esquemas de assimilação. Quando a preocupação do professor é basicamente a transmissão de conhecimentos, ou seja, conteúdos, acontecem os comportamentos de desinteresse e de desprazer.

\section{A cooperação e a atividade operatória}

De acordo com Aebli (1973), a pesquisa pessoal do aluno conduz à construção das operações, a partir de um problema, objeto da pesquisa. Quando esse objeto é de ordem cognitiva, os conhecimentos adquiridos tornam-se hábitos intelectuais rígidos. Para que isso não ocorra, sugere-se a cooperação dos alunos nos trabalhos de pesquisa, com o objetivo de favorecer conhecimentos adquiridos com mobilidade operatória, capazes de generalização, extensas aplicações e desenvolvimentos novos. Somente o pensamento operatório torna a criança capaz de participar das atividades de um grupo.

Possuindo uma inteligência que só conhece hábitos e intuições egocêntricas, a criança não pode compreender pontos de vista diferentes do seu, o que a torna inapta para a cooperação. Mas, uma vez que a formação da inteligência operatória está em marcha, a discussão em comum, exigindo a adaptação de cada um à posição dos outros, tende a tornar móvel e lógico o pensamento da criança. A aplicação que a escola deve fazer desses ensinamentos psicológicos é evidente. Na medida do possível, deve dar uma forma socializada às atividades dos alunos. Este postulado é realizado na discussão em comum e no trabalho em equipes (Aebli, 1973, pp. 109-110).
Mas o que torna o trabalho em equipe uma forma de atividade socializada, é igualmente o fato de implicar discussão, intercâmbio de ideias entre os elementos dos grupos. Os estudos de Piaget nos informam sobre o efeito favorável da discussão em comum na construção das noções e operações. No início dos trabalhos grupais, muitos alunos apresentam tendência para encarar um problema dado unicamente de seu próprio ponto de vista. Durante as discussões, cada aluno tem a oportunidade de descobrir que seus pares encaram o objeto de estudo a partir de outro ponto de vista e, por conseguinte, propõem soluções diferentes da sua. Se vários grupos trabalham na solução do mesmo problema, podem ser reunidos depois para comparar e discutir os diferentes caminhos de solução. Com relação à cooperação, Piaget (2008, p. 184) revela:

Do ponto de vista intelectual, é ela que está mais apta favorecer o intercâmbio real do pensamento e da discussão, isto é, todas as condutas suscetíveis de educarem o espírito crítico, a objetividade e a reflexão discursiva. Do ponto de vista moral, ela chega a um exercício real dos princípios da conduta, e não só a submissão exterior. Dizendo de outra maneira, a vida social, penetrando na classe pela colaboração efetiva dos alunos e a disciplina autônoma do grupo, implica o ideal mesmo de atividade que precedentemente descrevemos como característico da escola moderna: ela é a moral em ação, como o trabalho 'ativo' é a inteligência em ato. Muito mais, a cooperação conduz a um conjunto de valores tais como o da justiça baseada na igualdade e o da solidariedade 'orgânica'.

Com base em suas palavras, é possível concluir que cooperar na ação é operar em comum, isto é, ajustar por meio de novas operações (as operações realizadas por cada um de seus pares). A cooperação e as operações agrupadas são, pois, uma única realidade focada em dois aspectos diversos, ou seja, é um meio de tornar comuns as operações de cada um.

Quando a socialização da criança progride, explica Oliveira Lima (1980), em decorrência de seu desenvolvimento mental, produz-se uma mudança profunda nos seus processos mentais. As interações entre as pessoas forçam o descongelamento das instituições e das crenças, exigindo reversibilidade, sem as quais é impossível a cooperação. Daí se conclui que, num certo momento do desenvolvimento, as práticas docentes devem centrar-se na socialização, como em dinâmicas de grupo. É possível que, a 
partir daí, os processos didáticos que compartimentalizam as crianças em sala de aula venham a sofrer profundas mudanças.

Nesse sentido, é importante acrescentar as palavras de Piaget (1998), registradas por Montoya (2004, p. 177):

a educação forma um todo, e a atividade que a criança executa com relação a cada uma das disciplinas escolares supõe um esforço de caráter e um conjunto de condutas morais, assim como supõe uma certa tensão da inteligência e mobilização de interesses. Esteja ocupada em analisar regras da gramática, em resolver um problema de matemático ou em documentar um ponto da história, a criança que trabalha 'ativamente' é obrigada, não só diante de si como diante do grupo social que é a classe ou a 'equipe' da qual faz parte, a comportar-se de modo muito diferente do aluno tradicional que escuta uma lição ou realiza um 'dever' escolar.

Para que a educação de crianças se torne oportunidades de construção de uma personalidade autônoma, conclui Seber (1997), é necessário o entendimento a respeito da criança e do processo de aprendizado; e nisso a teoria piagetiana pode nos ajudar certamente. Conhecendo melhor as crianças, os professores terão chances de realizar um bom trabalho e com o conjunto desses conhecimentos haverá a esperança de, pelo menos, transformar as escolas em instituições que dignifiquem o homem.

\section{0 enfoque socioconstrutivista': Uma alternativa vygotskyniana}

As ideias construtivistas que floresceram na década de 1980 transformaram-se em uma resposta para a busca de educadores e pesquisadores por um suporte teórico que auxiliasse a solucionar o grande problema da educação que até hoje enfrentamos.

De forma similar, a partir da década de 1990, muitos educadores passaram a desenvolver suas práticas baseando-se em nova perspectiva teórica denominada socioconstrutivismo, oriundo da psicologia histórico-cultural de Lev Semenovich Vygotsky. Sob a ótica de Pimentel (1999), tendo em vista que a relação entre teoria e prática constitui um permanente desafio, é necessário destacar que essa tensão entre ambos, ocorreu com o construtivismo como ocorre também com relação ao referencial teórico vygotskyniano. Para fundamentar uma concepção de educação, é preciso lembrar que as produções de Vygotsky não podem ser consideradas como uma teoria plenamente organizada como argumenta a autora:

Para qualificar o conjunto de sua obra, efetivamente, como um sistema explicativo completo e articulado, é necessário rever e ponderar sobre aspectos que denotam algumas lacunas e contradições teórico-metodológicas. Sua produção aparenta ser composta de "textos jovens, escritos com entusiasmo e pressa" (Pimentel, 1999, p. 15).

Além disso, é necessário levar em conta que a abordagem vygotskyniana para a realidade atual brasileira merece um cuidadoso trabalho de adaptação ao contexto e ao seu momento histórico.

\section{A interação social e a perspectiva histórico-cultural}

A interação social, na proposição de Vygotsky, é enfocada como um processo interativo-comunicativo. Para compreendê-lo, será necessário considerar a noção de intersubjetividade em que o outro existe como princípio para a constituição do sujeito, dado que todas as funções superiores (psíquicas) originam-se das interações sociais entre indivíduos humanos.

0 processo de ensinar caracteriza-se como uma ação intersubjetiva com atribuições, trocas e transformações de sentidos, ao mesmo tempo que se constroem, com certa estabilidade, os significados definidos como "conteúdos" da aprendizagem realizada.

Dessa maneira, a interação professor-aluno e alunos entre si tem um caráter marcadamente dialógico; todas as funções no desenvolvimento da criança surgem duplamente: primeiramente, no nível social, ou seja, interpessoal; e, posteriormente, no nível individual (intrapessoal). É preciso considerar que este processo ocorre no interior de atividades mediadas. É a partir das relações sociais que as funções psicológicas superiores se desenvolvem na perspectiva vygotskyniana - as atividades da criança, desde o seu

\footnotetext{
1 Gostaríamos de esclarecer que o termo "socioconstrurivismo" se refere a um desmembramento que os teóricos da educação fizeram da Teoria Histórico-Cultural de Vygotsky.
}

Psicol. Argum. 2013 jul./set., 31 (74), 483-494 
nascimento, adquirem um significado próprio em um sistema de comportamento social, pois a relação entre objeto e criança e, de forma inversa, entre criança e objeto são mediados pelo outro.

Mello (2004), com base em Vygotsky, esclarece que as funções psíquicas humanas, tais como o pensamento, as linguagens oral e escrita, o cálculo, o controle da própria conduta, antes de se tornarem internas ao indivíduo, necessitam ser experimentadas nas relações entre as pessoas; não se desenvolvem espontaneamente, ou seja, não existem no indivíduo como uma potencialidade, são antes de mais nada, vivenciadas inicialmente sob a forma interpsíquica (entre pessoas) para, só depois assumirem a forma de atividade intrapsiquíca (dentro da pessoa). Conclui-se, assim, que o trabalho docente é fundamental para dirigir de modo intencional o processo educativo. Do ponto de vista da teoria histórico-cultural, o educador deverá trabalhar para garantir a reprodução em que cada novo ser humano precisa se apropriar das qualidades e aptidões humanas já criadas pelos homens no decorrer de suas vidas, garantidas pela transmissão da cultura.

\section{$\mathbf{O}$ desenvolvimento e a aprendizagem}

São temas centrais dos trabalhos do autor a aprendizagem, o desenvolvimento e as relações entre eles. Oliveira (1993) explica que, além de sua preocupação constante com a questão do desenvolvimento, paralelamente expõe a importância dos processos de aprendizado.

Para Vygotsky, de acordo com Oliveira (1993, p. 56),

... desde o nascimento da criança, o aprendizado está relacionado ao desenvolvimento e é 'um aspecto necessário e universal do processo de desenvolvimento das funções psicológicas culturalmente organizadas e especialmente humanas'. Existe um percurso de desenvolvimento, em parte definido pelo processo de maturação do organismo individual, pertencente à espécie humana, mas é o aprendizado que possibilita o despertar de processos internos de desenvolvimento que, não fosse o contato do indivíduo com certo ambiente cultural, não ocorreriam.

O que será então aprendizagem ou aprendizado para Vygotsky?
É o processo pelo qual o indivíduo adquire informações, habilidades, atitudes e valores em seus contatos com a realidade, o meio ambiente, as outras pessoas. Convém não esquecer que a ideia de aprendizado incluí a interdependência dos indivíduos envolvidos no processo.

Com base em Van Der Veer e Valsiner (1996), Vygotsky compreendia que aprendizagem e desenvolvimento são processos distintos e não poderiam ser confundidos; porém, o desenvolvimento da criança não pode ser visto de forma isolada em relação ao processo de aprendizagem. Isto o levou a concluir que o ensino só é efetivo quando aponta para o caminho do desenvolvimento.

As características inatas do indivíduo, conforme (Mello, 2004), são condição essencial para seu desenvolvimento, mas são insuficientes, pois a força motora em relação a esse desenvolvimento é inexistente. Em outros termos, com base na teoria histórico-cultural, sem a cultura, o desenvolvimento tipicamente humano não ocorrerá, conclui-se, então, que a aprendizagem antecede ao desenvolvimento, possibilitando-o e impulsionando-o.

Camargo (1999) expõe que o papel da escola é tornar cotidiano o conhecimento científico, isto é, a ciência deve tornar-se vinculada à vida humana, acarretando transformação de significados, e basicamente, de sentidos. Por conseguinte, o professor deve ser mediador, ao aproximar os saberes de seus alunos e da escola e valorizar as experiências do sujeito na busca do conhecimento sistematicamente organizado. A ação mediadora é capaz de movimentar os processos internos, permitindo a produção de vínculos entre o conhecimento que o indivíduo já possui e os novos conhecimentos a serem adquiridos. Quando o conhecimento científico aproxima-se do cotidiano, a ciência perde a aura de que seu domínio é restrito aos cérebros mais iluminados. Ela só terá sentido quando ancora a práxis do homem e a prática, sendo melhor compreendida com a explanação científica. Como teoria e prática são inseparáveis, conforme Mello (2004), não há qualquer razão em criar entre elas uma dicotomia.

Com essa reflexão, observa-se que o processo de aprendizagem é sempre ativo (sujeito que aprende). Portanto, ao apropriar-se de um objeto, é necessário que o aluno reproduza, com o objeto, o uso social para o qual ele foi criado. Esse processo, por conseguinte, exigirá a atuação do adulto junto com a criança, para que ela se aproprie de um objeto ou de uma habilidade, realizando ela própria as 
atividades. Oliveira (1993, p. 62) revê uma afirmação de Vygotsky que diz que "o único bom ensino é aquele que se adianta ao desenvolvimento". Os procedimentos cotidianos que ocorrem na escola como demonstrações, assistência, fornecimento de pistas, instruções, são consideradas fundamentais na promoção do "bom ensino". A criança não tem condições de percorrer, sozinha, o caminho do aprendizado. A intervenção de outras pessoas (professor e as demais crianças) tornam o aprendizado uma conquista na base de construções pessoais.

\section{0 desenvolvimento proximal}

É interessante registrar como Vygotsky descreveu de modo detalhado o conceito de zona de desenvolvimento proximal. Em uma palestra proferida em 1933, o autor mencionou que alguns pesquisadores como Binet costumavam pensar que não se pode começar a ensinar crianças se elas não tiverem atingido um determinado nível de desenvolvimento. Assim foram estabelecidos os limiares mínimos a partir dos quais o ensino de conteúdos escolares poderia ser iniciado. 0 modo de estabelecer esses limiares era pedir à criança para solucionar sozinha algum trabalho ou teste específico (Van Der Veer \& Valsiner, 1996) com a finalidade de estabelecer os períodos apropriados para aprendizagem das várias capacidades intelectuais. É possível estabelecer o potencial de uma criança para aprender um dado conteúdo ou habilidade, afirma Vygotsky em Van Der Veer e Valsiner (1996) e para chegar a isto voltou-se para a área dos testes de inteligência e para o conceito de zona de desenvolvimento proximal. Assim, Vygotsky produziu uma definição a respeito desse desenvolvimento:

A zona do desenvolvimento proximal da criança é a distância entre seu desenvolvimento real, determinado com a ajuda de tarefas solucionadas de forma independente, e o nível de seu desenvolvimento potencial, determinado com a ajuda de tarefas solucionadas pela criança com a orientação de adultos e em cooperação com seus colegas mais capazes (Vygotsky 1933 citado por Van Der Veer \& Valsiner, 1996, p. 365).

O nível de desenvolvimento real e independente era característico das habilidades intelectuais que a criança já havia dominado, explica Vygotsky, e ele representava as funções já amadurecidas, os resultados de ontem. Entretanto, o desempenho da criança em cooperação com seus pares e adultos era característico de seu desempenho futuro e revelava os resultados de amanhã. Dessa forma todos os amanhãs da vida da criança representariam as potencialidades (desenvolvimento potencial), assim, a investigação do desenvolvimento proximal passa a representar um dos instrumentos mais poderosos da atividade educacional. Em outras palavras, a aprendizagem somente ocorrerá quando o ensino incidir na zona do desenvolvimento proximal. Explica Mello (2004), quando ensinamos a criança aquilo que ela já sabe não ocorreu aprendizagem e nem desenvolvimento. Da mesma forma se for ensinado a ela algo que está além de suas possibilidades em aprender, ocorre o mesmo fenômeno, nada de aprendizagem, mesmo com o auxilio de outras pessoas. Cabe à escola portanto, dirigir o trabalho educativo para fases de desenvolvimento ainda não alcançadas pela criança. É fundamental a interferência intencional do adulto educador e de seu planejamento, bem como, as atividades grupais de crianças de diferentes idades e níveis de desenvolvimento.

Quando se descobre, explica Vygotsky (1984), as relações reais entre o processo de desenvolvimento e a capacidade de aprendizado, determinar-se-á a existência de pelo menos dois níveis de desenvolvimento. 0 primeiro pode ser denominado nível de desenvolvimento real e que se baseia no nível desenvolvimental das funções mentais da criança já estabelecidas como resultado de certos ciclos de desenvolvimento já completados. Ao tornar claras essas explicações Vygotsky (1984), assim o faz:

Quando determinamos a idade mental de uma criança usando testes, estamos quase sempre tratando do nível de desenvolvimento real. Nos estudos do desenvolvimento mental das crianças, geralmente admite-se que só é indicativo da capacidade mental das crianças aquilo que elas conseguem fazer por si mesmas. Apresentamos às crianças uma bateria de testes ou várias tarefas com graus variados de dificuldades e julgamos a extensão de seu desenvolvimento mental baseados em como e com que grau de dificuldade elas os resolvem (Vygotsky, 1984, pp. 95-96).

Ao responder "o que é nível de desenvolvimento real", ou, mais simplesmente, "o que revela a solução de problemas pela criança de forma mais independente", o autor expõe que o nível de desenvolvimento real de uma criança define funções que já amadureceram, ou seja, os produtos finais do desenvolvimento.

Psicol. Argum. 2013 jul./set., 31 (74), 483-494 
Se uma criança pode fazer tal e tal coisa independentemente, isso significa que as funções para essas soluções já amadureceram nela. Por outro lado, a zona de desenvolvimento proximal, detectada por meio de problemas que a criança não pode resolver independentemente, fazendo-o somente com assistência, é definida por aquelas funções ainda não amadurecidas, mas que estão em processo de maturação, funções que, certamente, amadurecerão, mas que estão no momento em estado embrionário.

Essas funções poderiam ser chamadas de 'brotos' ou 'flores' do desenvolvimento, ao invés de 'frutos' do desenvolvimento. 0 nível de desenvolvimento real caracteriza o desenvolvimento mental retrospectivamente enquanto a zona de desenvolvimento proximal caracteriza o desenvolvimento prospectivamente (Vygotsky, 1984, p. 97).

A zona de desenvolvimento proximal nos autoriza a delinear o futuro imediato da criança e seu estado dinâmico de desenvolvimento, facilitando o acesso não somente ao que foi atingido pelo desenvolvimento como também o que está em processo de maturação. 0 estado de desenvolvimento mental da criança só será determinado quando forem revelados os seus níveis: o nível de desenvolvimento real e o nível de desenvolvimento proximal.

Oliveira (1993) chama nossa atenção para a expressão "zona de desenvolvimento proximal" que aparece às vezes nas traduções para a língua portuguesa como "zona de desenvolvimento potencial". Observem-se as palavras da autora com relação ao termo "potencial”: “... para compreender adequadamente o desenvolvimento devemos considerar não apenas o nível de desenvolvimento real da criança, mas também seu nível de desenvolvimento potencial..." (Oliveira, 1993, p. 59).

Observem-se as explicações de Martins (1999), nas quais também aparece essa expressão:

Vygotsky desenvolveu este conceito para discutir as relações entre desenvolvimento e aprendizado. A zona de desenvolvimento proximal descreve a distância entre o nível de desenvolvimento real (NDR) da criança - constituído por funções da criança já completadas pela criança em seu desenvolvimento - e o nível de desenvolvimento potencial (NDP) - determinado através da solução de problemas sob a orientação de um adulto ou em colaboração com companheiros mais capazes (Martins, 1999, p. 55).
Van Der Veer e Valsiner (1996) revelam o otimismo pedagógico de Vygotsky, quando faz a previsão do desenvolvimento. Segundo este autor, a zona de desenvolvimento proximal pode revelar os resultados de amanhã, e consiste em um meio magnífico de prognóstico. Ele sugeriu, em resumo, a medição de duas grandezas: desempenho independente e desempenho conjunto com ajuda e afirmou que o desenvolvimento futuro do primeiro era totalmente determinado pelo último. As crianças, quando em grupos para executar tarefas ou solucionar tarefas podem beneficiar-se em razão da capacidade de imitar as atividades de seus parceiros mais experientes. Quando as crianças podem imitar suas atividades no momento atual, certamente estas serão executadas de forma independente no futuro próximo.

0 trabalho que Vygotsky concluiu com referência à zona de desenvolvimento proximal e a relação entre aprendizagem e desenvolvimento cognitivo é o aspecto mais conhecido de sua contribuição às ciências da educação.

\section{As palavras e os pensamentos}

Vygotsky começou seus trabalhos relacionados ao pensamento e à palavra com base na observação global de que fala e pensamento têm origens distintas, seguem caminhos diferentes e independentes, antes da ocorrência da estreita ligação entre esses dois fenômenos. Essa trajetória do pensamento desligado da linguagem e a trajetória da linguagem independente do pensamento, em um determinado momento do desenvolvimento filogenético, unem-se e o pensamento torna-se verbal e a linguagem racional. Essa associação ocorre em razão da necessidade de intercâmbio dos indivíduos enquanto convivem e trabalham. Para agir coletivamente e de formas cada vez mais especificadas e $\backslash$ ou sofisticadas, o grupo humano passou a criar um sistema de comunicação a fim de trocar informações. Os significados, portanto, eram necessariamente compartilhados. É o momento em que o biológico transforma-se no sócio-histórico. Nessa análise das relações entre pensamento e linguagem, a questão do significado torna-se seu ponto mais importante.

Segundo Oliveira (1993), o significado constitui-se em um elemento essencial da palavra e, ao mesmo tempo, um ato de pensamento, uma vez que o 
significado da palavra é inerentemente uma generalização ou um conceito. É no significado da palavra que o pensamento e a fala se unem em pensamento verbal. Além da possibilidade de comunicação entre as pessoas, o significado define um modo de organização do mundo real. A verdadeira comunicação humana, enfatiza Vygotsky (1991), pressupõe uma atitude generalizante. As formas mais complexas da comunicação são possíveis somente porque o pensamento do homem reflete uma realidade conceitualizada.

O processo de significação consiste na interpretação de um signo (um sinal, uma palavra escrita ou falada) e sua relação com um objeto, uma pessoa ou um fenômeno e é de extrema importância para que ocorra nas relações intersubjetivas educacionais, um processo de aprendizagem. A criança, através de negociações de sentidos a respeito de um objeto de conhecimento, passará a elaborar os significados correspondentes a esse conhecimento e simultaneamente, estabelecerá formas novas de pensar, graças à mediação com o professor e seus pares nas sucessivas mediações semióticas. No início da vida, a criança faz uso da linguagem socializada com o objetivo de comunicar-se ou manter contatos sociais. Com o desenvolvimento, ela tornar-se-á capaz de fazer uso da linguagem como instrumento de pensamento, com a função de adaptação social.

\section{Orientações derivadas da teoria sócio-histórica}

As orientações derivadas dessa teoria tendem para a preocupação de que a educação se realize em condições ótimas para promover o desenvolvimento pleno e harmônico das crianças. As palavras de Mello representam sinais que orientam as ações dos educadores:

... as possibilidades da criança e seu desenvolvimento harmônico não se criam pelo ensino forçado, antecipado, dirigido a diminuir a infância, a converter, antes do tempo, a criança pequena em pré-escolar e o pré-escolar em escolar. É indispensável, ao contrário, o desenvolvimento máximo das formas especificadamente infantis de atividade lúdica, prática e plástica e também da comunicação das crianças entre si e entre os adultos. É sobre essa base que se deve realizar a formação orientada ao desenvolvimento daquilo que constitui o bem mais valioso da pessoa: a inteligência e a personalidade (Mello, 2004, p. 154).

\section{Considerações finais}

Nestas breves considerações, esperamos ter realizado uma análise compreensiva dos enfoques tradicionalista, construtivista e socioconstrutivista na educação brasileira e suas implicações na profissão docente. Apresentamos esses três grandes núcleos como geradores de questionamentos sobre a complexidade real do contexto educacional e suas especificidades. Cada qual com seu referencial teórico que justifica a prática de certos métodos de ensino e as concepções a respeito da aprendizagem.

O que fica de toda essa discussão é que a formação técnico-científica não é o bastante para o professor; é fundamental - o que brilhantemente foi colocado por Seber (1997) — o entendimento a respeito da criança e de seu aprendizado. Conhecendo melhor as crianças, os professores terão chances de realizar um bom trabalho e com o conjunto desses conhecimentos haverá a esperança de, pelo menos, transformar as escolas em instituições que dignifiquem o homem. Com isso, há possibilidade de que a educação infantil oportunize a essas crianças a construção de uma personalidade autônoma.

\section{Referências}

Aebli, H. (1973). Didática psicológica: Aplicação à didática da psicologia de Jean Piaget. (2. ed.). (J. T. D’Olin Marote, Trad.). São Paulo: Nacional.

Bee, H. (1996). A criança em desenvolvimento. (7. ed.). Porto Alegre: Artmed.

Camargo, J. S. (1999). Interação professor-aluno: A escola como espaço interativo. In J. B. Martins (Org.). Na perspectiva de Vygotsky. (pp. 67-80). São Paulo: Quebra Nozes.

Martins, J. P. (1999). Exercício social e internalização. In J. B. Martins (Org.). Na perspectiva de Vygotsky. (pp. 51-65). São Paulo: Quebra Nozes.

Mello, S. A. (2004). A escola de Vygotsky. In K. Carrara (Org.). Introdução à psicologia da educação: Seis abordagens. (pp. 135-155). São Paulo: Avercamp.

Montoya, A. O. D. (2004). Contribuições da psicologia e epistemologia genéticas para a educação. In K. Carrara (Org.). Introdução à psicologia da educação: Seis abordagens (pp. 157-186). São Paulo: Avercamp.

Psicol. Argum. 2013 jul./set., 31 (74), 483-494 
Oliveira Lima, L. (1980). Por que Piaget? A educação pela inteligência. São Paulo: Senac.

Oliveira, M. K. (1993). Vygotsky - Aprendizado e desenvolvimento: Um processo sócio-histórico. São Paulo: Scipione.

Papalia, D. E., \& Olds, S. W. (2000). Desenvolvimento humano. (7. ed.). Porto Alegre: Artmed.

Piaget, J. (1969). Seis estudos de psicologia. (3. ed.). São Paulo: Forense.

Piaget, J. (2008). Psicologia e Pedagogia: A resposta do grande psicólogo aos problemas do ensino. (9. ed.). (D. A. Lindoso \& R. M. R. Silva, Trad.). Rio de Janeiro: Forense Universitária.

Pimentel, A. (1999). Intersubjetividade e aprendizagem escolar. In J. B. Martins (Org.). Na perspectiva de Vygotsky. (pp. 13-26). São Paulo: Quebra Nozes.
Rappaport, C. R. (1981). Modelo piagetiano. In C. R. Rappaport, W. R. Fiori, C. Davis. Teorias do desenvolvimento: Conceitos fundamentais. (Vol. 1, pp. 51-75). São Paulo: E.P.U.

Seber, M. G. (1997). Piaget: O diálogo com a criança e o desenvolvimento do raciocínio. São Paulo: Scipione.

Souza, M. L Filho. (2008). Relações entre aprendizagem e desenvolvimento em Piaget e em Vygotsky: Dicotomia ou compatibilidade? Diálogo Educacional, $8(23), 265-275$.

Van Der Veer, R., \& Valsiner, J. (1996). Vygotsky: Uma síntese. (C. M. Bartalloti, Trad.). São Paulo: Loyola.

Vygotsky, L. S. (1984). A formação social da mente. (J. Cipolla Neto, L. S. M. Barreto \& S. C. Afeche, Trad.). São Paulo: Martins Fontes.

Vygotsky, L. S. (1991). Pensamento e linguagem. (J. L. Camargo, Trad.). São Paulo: Martins Fontes. 